\title{
BRPKM
}

Buletin Riset Psikologi dan Kesehatan Mental

http://e-journal.unair.ac.id/index.php/BRPKM

e-ISSN: 2776-1851

ARTIKEL PENELITIAN

\section{Hubungan antara Self-Esteem dengan Kecenderungan Anorexia Nervosa pada Remaja Putri}

\author{
SEKAR JINGGA DIWANANDA ISLAMY \& IKA YUNIAR CAHYANTI* \\ Fakultas Psikologi Universitas Airlangga
}

\begin{abstract}
ABSTRAK
Penelitian ini bertujuan untuk mengetahui hubungan antara self-esteem dengan kecenderungan anorexia nervosa pada remaja putri. Metode penelitian menggunakan metode kuantitatif melalui survei. Self-esteem diukur menggunakan Rosenberg Self-esteem Scale (RSES) yang telah diadaptasi ke dalam bahasa Indonesia dengan koefisien reliabilitas 0,8689. Kecenderungan anorexia nervosa diukur menggunakan Eating Attitude Test 26 (EAT-26) yang telah diadaptasi ke dalam bahasa Indonesia, memiliki koefisien reliabilitas 0,872. Subjek pada penilitian ini adalah remaja putri berusia 15-22 tahun berjumlah 245 orang. Analisis data menggunakan teknik korelasi Pearson Product Moment. Hasil menunjukkan adanya hubungan negatif yang signifikan antara self-esteem dengan kecenderungan anorexia nervosa pada remaja putri $(\mathrm{r}=-0,136 ; \mathrm{p}=0,033)$. Artinya, semakin tinggi tingkat self-esteem maka semakin rendah tingkat kecenderungan anorexia nervosa, sebaliknya, semakin rendah tingkat selfesteem maka semakin tinggi tingkat kecenderungan anorexia nervosa.
\end{abstract}

Kata kunci: kecenderungan anorexia nervosa, self-esteem

\section{ABSTRACT}

This study aims to determine the relationship between self-esteem and anorexia nervosa tendency on female adolescent. The research is using quantitative methods through surveys. Self-esteem measured using Rosenberg Self-esteem Scale (RSES) which has been adapted into Indonesian which has a reliability coefficient of 0.8689. Anorexia nervosa tendency measured using Eating Attitude Test 26 (EAT-26) which has been adapted into Indonesian and has a reliability coefficient of 0.872 . The subjects in this study were young women aged 15-22 years with total 245 people. Data analysis using Pearson Product Moment correlation technique. The results showed that there was a significant negative relationship between self-esteem and anorexia nervosa tendencies in female adolescents $(\mathrm{r}=-0.136$; $\mathrm{p}=0.033$ ). Means, the higher the level of self-esteem, the lower the tendency for anorexia nervosa, otherwise, the lower the level of self-esteem, the higher the tendency for anorexia nervosa.

Keywords: anorexia nervosa tendency, self-esteem

Buletin Penelitian Psikologi dan Kesehatan Mental (BRPKM), 2021, Vol. 1(1), 90-911

*Alamat korespondensi: Fakultas Psikologi Universitas Airlangga, Kampus B Universitas Airlangga Jalan Airlangga 4-6 Surabaya 60286. Surel: ika.yuniar@psikologi.unair.ac.id

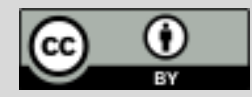

Naskah ini merupakan naskah dengan akses terbuka dibawah ketentuan the Creative Common Attribution License (CC-BY-4.0) (http://creativecommons.org/licenses/by/4.0), sehingga penggunaan, distribusi, reproduksi dalam media apapun atas artikel ini tidak dibatasi, selama sumber aslinya disitir dengan baik. 


\section{PEN D A H U L U A N}

Masa remaja merupakan salah satu tahapan perkembangan yang akan dialami setiap individu. Masa remaja merupakan masa transisi dari masa kanak-kanak menuju masa dewasa. Pada masa ini, remaja akan mengalami berbagai perubahan dalam hidupnya. Perubahan tersebut meliputi perubahan biologis, memiliki pengalaman dan pengetahuan mengenai hal-hal baru, memiliki tugas-tugas perkembangan yang berbeda dari tahap perkembangan sebelumnya, serta mulai berpikir secara abstrak dan idealistik (Santrock, 2010). Perkembangan pada masa remaja ditandai dengan adanya masa pubertas yang memberikan dampak pada perubahan diri individu, salah satunya adalah perubahan fisik. Perubahan fisik seperti perubahan bentuk tubuh menjadi perhatian khusus di kalangan remaja. Perubahan fisik yang utamanya akan dialami oleh remaja putri adalah ukuran payudara yang membesar, pinggul yang membesar, bertambahnya berat badan dan tinggi badan.

Pada masa remaja, individu memiliki tugas-tugas perkembangan yang berbeda dari masa perkembangan sebelumnya. Salah satu tugas perkembangan yang harus dipenuhi oleh remaja menurut Havighurst (1972, dalam Santrock, 2007) adalah menerima keadaan dirinya dan memanfaatkannya dengan baik. Remaja putri yang mampu memenuhi tugas perkembangan tersebut akan merasa puas pada perubahan bentuk tubuhnya sebab ia menerima keadaan dirinya. Pada kenyataannya, dalam menghadapi perubahan bentuk tubuh akibat pengalaman pubertas tersebut, remaja putri lebih sering merasa kurang puas akan bentuk tubuhnya jika dibandingkan dengan remaja putra (Bearman, dkk., 2006).

Saat ini, di kalangan remaja putri terdapat acuan bentuk tubuh yang ideal agar dinilai menarik yaitu tubuh yang kurus, tinggi, serta langsing (Ratnawati \& Sofiah, 2012). Di era digital seperti saat ini, penggunaan sosial media sebagai sumber informasi marak digunakan. Pada sosial media seperti Instagram, banyak sekali iklan mengenai obat pelangsing tubuh. Iklan tersebut menawarkan khasiat dari penggunaan obat pelangsing, yaitu menurunkan berat badan secara instan dan cepat. Hal itu bisa saja memberikan dampak buruk bagi konsumen, sebab untuk melakukan penurunan berat badan yang sesuai dengan aturan agar tetap aman, membutuhkan proses dan waktu tertentu, tidak terjadi secara cepat dan instan. Selain itu, pada dunia peragaan busana seringkali menampilkan model yang memiliki bentuk tubuh kurus dan langsing, serta pada program televisi juga seringkali menampilkan selebriti sukses bertubuh kurus dan langsing yang menyebabkan konsumen khususnya remaja putri sangat ingin memiliki tubuh yang tinggi, kurus, dan langsing seperti apa yang mereka lihat di media sosial (Santrock, 2010).

Memiliki bentuk tubuh yang ideal juga akan membuat remaja putri merasa lebih diterima oleh temanteman sebayanya. Hal tersebut membuat remaja putri melakukan usaha agar tubuhnya tetap kurus dan langsing sesuai dengan standar yang ada. Demi mendapatkan bentuk tubuh yang tetap kurus, langsing, dan sesuai dengan standar kecantikan yang ada, remaja putri akan melakukan pengurangan berat badan dengan membatasi pola makan, bahkan tak jarang mereka menggunakan obat pencahar. Perilaku pembatasan pola makan atau dietting apabila dilakukan dengan baik dan benar, maka akan menghasilkan tubuh yang ideal dan sehat, namun jika perilaku tersebut dilakukan secara berlebihan dan tidak sesuai dengan aturan maupun kebutuan, maka akan memberikan dampak tidak baik terhadap kesehatan, bahkan membuat individu mengalami pengurangan berat badan yang tidak normal. Hal tersebut juga dapat mengacu pada terjadinya kecenderungan anorexia nervosa.

Anorexia nervosa merupakan salah satu jenis gangguan makan di mana individu memiliki kesalahan berpikir mengenai berat badan serta bentuk badan mereka (American Psychiatric Association, 1994). Individu akan melakukan berbagai cara untuk tetap kurus dengan melakukan diet ketat dan terkadang 
berlebihan serta dapat membahayakan dirinya hingga dapat menyebabkan kematian (Santrock, 2010). Individu yang mengalami kecenderungan anorexia nervosa menurut PPDGJ III akan mempertahankan berat badannya di bawah berat badan normal yang didasarkan pada indeks massa tubuh (IMT). Pada penelitian yang dilakukan oleh Tantiani \& Syafiq (2008), subjeknya yang mengalami kecenderungan anorexia nervosa sebanyak 1 orang memiliki IMT di bawah normal, dan 28 orang memiliki IMT normal. Kecenderungan anorexia nervosa banyak terjadi di kalangan remaja Sekolah Menengah Atas dan Perguruan Tinggi, khususnya pada remaja putri. Selain itu, menurut Burrows \& Cooper (2002) gangguan makan banyak terjadi pada perempuan dibandingkan pada laki-laki, sebab pada perempuan berat dan bentuk tubuh menjadi hal yang sangat diperhatikan sehingga dapat menimbulkan tekanan sosial yang lebih tinggi, sedangkan pada laki-laki tekanan sosial mengenai berat dan bentuk tubuh lebih rendah.

Berdasarkan National Eating Disorders (2018) secara global, antara 0,9\%-2\% perempuan mengalami anorexia nervosa, sebanyak 1,1\%-3\% dialami oleh remaja putri, dan remaja pada usia 15-24 tahun yang memiliki anorexia nervosa berisiko 10 kali lipat untuk meninggal dibandingkan dengan teman sebayanya. Sebanyak 1\% remaja putri di Amerika Serikat mengalami anorexia nervosa, 2,6\% mahasiswa putri di Norway, dan 1,3\% mahasiswa di Itali juga mengalami anorexia nervosa (Makino dkk., 2004 dalam Krisnani, dkk., 2017). Di Indonesia, beberapa penelitian seperti yang dilakukan oleh Syarafina \& Probosari (2014) menunjukkan 67,8\% remaja di Semarang mengalami kecenderungan gangguan makan dengan prevalensi 8,5\% anorexia nervosa. Remaja putri yang mengalami kecenderungan anorexia nervosa akan memilih untuk menolak makanan, bahkan tak jarang mereka memilih untuk tidak makan meskipun mereka merasa lapar. Tantiani \& Syafiq (2008) menyatakan sebanyak 37,3\% remaja di Jakarta mengalami gangguan makan dengan prosentase $11,6 \%$ remaja mengalami anorexia nervosa. Remaja yang mengalami gangguan makan tersebut diketahui melakukan pembatasan pola makan sehari-hari bahkan tak jarang mereka tidak makan. Mereka juga memuntahkan makanan secara paksa tepat setelah mereka selesai menghabiskan makanan dengan memasukkan jari ke kerongkongan atau menggunakan obat pencahar. Individu menolak atau bahkan tidak makan karena takut akan adanya peningkatan pada berat badan yang akan memengaruhi bentuk tubuh mereka.

Kecenderungan anorexia nervosa pada remaja putri diakibatkan oleh pandangan mereka terhadap bentuk tubuhnya yang membuat mereka merasa tidak puas. Hal tersebut menjadikan remaja putri merasa penampilannya tidak menarik dan tidak sesuai dengan tuntutan lingkungan sosialnya, sehingga membuat remaja putri juga tidak bisa menilai dan menerima dirinya dengan baik. Apabila mereka tidak bisa menilai dan menerima dirinya dengan baik, mereka juga tidak bisa menghargai dirinya sendiri. Oleh sebab itu, kecenderungan anorexia nervosa dapat terjadi akibat adanya gambaran bentuk tubuh individu terhadap dirinya yang bisa memengaruhi bagaimana individu menilai serta menganggap berharga dirinya, dan mampu menerima kondisi dirinya yang disebut dengan self-esteem.

Self-esteem merupakan sikap dan tingkah laku individu dalam menilai berharga atau tidaknya diri individu tersebut, berupa penolakan atau penerimaan terhadap dirinya (Heatherton \& Polivy, 1991). Menurut Rosenberg (1989), self-esteem memiliki dua makna, yaitu pandangan individu terhadap kemampuannya dan penilaian individu terhadap dirinya. Menurut Robins, dkk (2002) self-esteem individu yang memasuki usia remaja akan mengalami penurunan, dan pada remaja putri penurunan self-esteem terjadi secara drastis karena adanya berbagai perubahan selama masa pubertas, terutama mengenai bentuk tubuh (Santrock, 2010). Impett, dkk (2008) menyatakan bahwa perubahan self-esteem pada remaja putri juga diakibatkan karena remaja putri menaruh perhatian besar pada hubungan sosial dan adanya kegagalan dalam memenuhi hubungan sosial tersebut. Menurut Syarafina \& Probosari (2014) penampilan fisik yang ideal menjadi daya tarik tersendiri bagi remaja putri untuk bisa memiliki 
hubungan sosial yang baik dengan teman sebayanya. Remaja putri bersaing demi mendapatkan tubuh yang ideal dengan melakukan berbagai cara, salah satunya adalah dengan melakukan diet ketat.

Remaja putri yang memiliki self-esteem tinggi akan mampu menilai dirinya secara positif, menerima dirinya dan menghargai dirinya dengan baik. Begitupun sebaliknya, remaja putri yang memiliki selfesteem rendah cenderung menilai dirinya secara negatif, tidak bisa menerima dan kurang menghargai dirinya sendiri. Self-esteem juga sangat berperan pada remaja putri dalam memandang bentuk tubuhnya. Remaja putri dengan self-esteem tinggi akan menghargai dirinya dan merasa puas terhadap bentuk tubuhnya. Remaja putri yang memiliki self-esteem tinggi juga tidak akan membandingkan bentuk tubuhnya dengan milik orang lain. Remaja putri yang memiliki self-esteem rendah tidak menghargai dirinya dan akan merasa tidak puas terhadap penampilan fisik terutama bentuk tubuhnya. Remaja putri dengan self-esteem rendah akan membandingkan bentuk tubuhnya dengan milik orang lain, serta berusaha menjadikan bentuk tubuhnya sesuai dengan standar ideal yang ada di lingkungan sosialnya (Tylka \& Sabik, 2010 dalam Talwar, 2012).

Penelitian yang dilakukan oleh (Talwar, 2012) menyebutkan bahwa self-esteem berperan penting dalam terjadinya gangguan makan. Self-esteem rendah menjadi salah faktor yang yang dapat menyebabkan individu mengalami gangguan makan (Button, dkk., 1996 dalam Talwar, 2012). Beals (2004) juga mengatakan bahwa individu dengan anorexia nervosa memiliki self esteem rendah yang membuat mereka memiliki keinginan menjadi kurus. Hal tersebut juga sejalan dengan penelitian yang dilakukan (Talwar, 2012) yang menunjukkan remaja putri yang mengalami gangguan makan ternyata juga memiliki self-esteem yang rendah. Lingkungan sosial yang juga menuntut remaja putri untuk tetap tampil cantik dan menarik dengan bentuk tubuh yang tinggi, kurus, serta langsing, membuat mereka tidak bisa menilai diri secara positif, dan kurang menghargai dirinya, serta membandingkan tubuhnya dengan orang lain. Sikap dan perilaku tersebut yang merupakan karakteristik dari self-esteem yang rendah. Beals (2004) juga mengatakan bahwa individu dengan self-esteem rendah akan melakukan berbagai cara untuk tetap kurus.

Berdasarkan paparan di atas, penulis tertarik melakukan penelitian mengenai self-esteem dan kecenderungan anorexia nervosa pada remaja putri. Tujuan dari penelitian ini adalah untuk mengetahui ada atau tidaknya hubungan antara self-esteem dengan kecenderungan anorexia nervosa pada remaja putri melalui pengujian secara empiris dan sistematis.

\section{Desain Penelitian}

\section{MET O D E}

Metode penelitian yang digunakan adalah metode kuantitatif korelasional yang bertujuan untuk mengetahui kekuatan dan arah hubungan antar variabel yang diteliti (Azwar, 2018). Pengumpulan data dalam penelitian ini menggunakan teknik survei yaitu dengan menyebarkan pertanyaan kepada responden menggunakan alat pengumpul data berupa kuesioner (Neuman, 2017). Variabel penelitian terdiri atas variabel independen yaitu self-esteem dan variabel dependen yaitu kecenderungan anorexia nervosa.

\section{Partisipan}

Kriteria partisipan yang harus dipenuhi dalam penelitian ini adalah remaja putri yang memiliki usia 1522 tahun. Teknik sampling yang digunakan dalam penelitian ini adalah teknik non-probabilitas. Teknik yang digunakan dalam penelitian ini untuk mendapatkan partisipan adalah teknik purposive sampling, yaitu dengan menentukan kriteria tertentu dalam pengambilan data sesuai dengan yang dibutuhkan 
dalam penelitian. Partisipan di minta untuk membaca informed consent terlebih dahulu, sebelum mengisi survei.

Partisipan terdiri atas remaja putri sebanyak 245 orang. Berdasarkan usia partisipan, sebanyak 5 orang $(2,04 \%)$ berusia 15 tahun, sebanyak 14 orang $(5,71 \%)$ berusia 16 tahun, sebanyak 29 orang $(11,84 \%)$ berusia 17 tahun, sebanyak 30 orang $(12,24 \%)$ berusia 18 tahun, sebanyak 25 orang $(10,20 \%)$ berusia 19 tahun, sebanyak 23 orang (9,39\%) berusia 20 tahun, sebanyak 56 orang $(22,86 \%)$ berusia 21 tahun, sebanyak 63 orang $(25,71 \%)$ berusia 22 tahun. Selain berdasarkan usia, partisipan dipilih berdasarkan Indeks Massa Tubuh (IMT) Nasional dengan kategori normal dan/atau kurus. Berdasarkan Indeks Massa Tubuh (IMT) sebanyak 188 orang (76,73\%) termasuk kategori normal, sebanyak 31 orang $(12,65 \%)$ termasuk kategori kurus tingkat ringan, dan sebanyak 26 orang $(10,61 \%)$ termasuk kategori kurus tingkat berat.

\section{Pengukuran}

Pada penelitian ini menggunakan alat ukur Rosenberg Self-esteem Scale (RSES) oleh Rosenberg (1965) yang telah diadaptasi oleh Azwar (2018) ke dalam bahasa Indonesia untuk mengukur self-esteem. Rosenberg Self-esteem Scale (RSES) memiliki koefisien reliabilitas $\alpha=0,8689$, terdiri atas 10 butir aitem dengan 4 pilihan jawaban berupa skala likert berturut-turut adalah "sangat tidak setuju (STS); tidak setuju (TS); setuju (S); sangat setuju (SS)". Alat ukur yang digunakan untuk mengukur kecenderungan anorexia nervosa adalah Eating Attitude Test 26 (EAT-26) oleh Garner, dkk (1982) yang kemudian yang telah diterjemahkan ke dalam bahasa Indonesia dan dimodifikasi oleh peneliti sebelumnya, yaitu Wijaya (2018) melalui professional judgement dan menghasilkan 14 butir aitem. Alat ukur EAT-26 memiliki koefisien reliabilitas $\alpha=0,872$ dengan 5 pilihan jawaban dalam bentuk skala likert yaitu tidak pernah, jarang, beberapa kali, sering, dan selalu.

\section{Analisis Data}

Analisis data menggunakan teknik analisis korelasi menggunakan Pearson's Product Moment. Sebelum melakukan analisis korelasi, terlebih dahulu dilakukan uji normalitas guna mengetahui data yang digunakan merupakan data parametrik atau non-parametrik. Uji normalitasi dilakukan dengan menggunakan teknik Kolmogorov-Smirnov. Proses analisis data dilakukan dengan bantuan program statistik SPSS version 22 for windows.

\section{HAS IL PEN ELITIAN}

Penulis melakukan uji analisis deskriptif terlebih dahulu untuk mengetahui gambaran karakteristik partisipan yang ada dalam penelitian. Berdasarkan uji analisis deskriptif diketahui jumlah partisipan dalam penelitian ini sebanyak 245 orang. Pada variabel self-esteem diketahui (Min=14; Max=39; $N=245$; $M=27,82 ; S D=4,042)$. Pada variabel kecenderungan anorexia nervosa diketahui (Min=14; Max=60; $N=245 ; M=28,73 ; S D=9,121$ ).

Analisis selanjutnya adalah penormaan kategorisasi untuk menempatkan subjek dalam kelompok terpisah dan mengetahui kecenderungan skor subjek. Hasil pada variabel self-esteem menunjukkan sebanyak 46 orang $(18,8 \%)$ memiliki self-esteem rendah, sebanyak 142 orang $(58,0 \%)$ memiliki selfesteem sedang, dan sebanyak 57 orang $(23,3 \%)$ memiliki self-esteem tinggi. Pada variabel kecenderungan anorexia nervosa sebanyak 35 orang (14,3\%) termasuk kategori kecenderungan

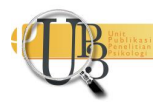


anorexia nervosa rendah, sebanyak 170 orang $(69,4 \%)$ termasuk kategori kecenderungan anorexia nervosa sedang, dan sebanyak 40 orang $(16,3 \%)$ termasuk kategori kecenderungan anorexia nervosa tinggi.

Penulis kemudian melakukan uji normalitas menggunakan teknik Kolmogorov-Smirnov untuk mengetahui distribusi data yang akan diuji apakah berdistribusi normal atau berdistribusi tidak normal. Berdasarkan uji normalitas data bersifat parametrik atau data berdistribusi normal $(p=0,200)$. Apabila data berdistribusi normal, analisis korelasi dapat dilakukan dengan menggunakan Pearson's Product Moment. Hasil analisis korelasi menunjukkan adanya hubungan negatif yang signifikan dan cenderung berkekuatan lemah antara self-esteem dengan kecenderungan anorexia nervosa $(r=-0,136 ; p=0,033)$. Penulis juga melakukan uji linearitas untuk mengetahui apakah hubungan antara kedua variabel penelitian linear atau tidak linear. Hasil uji linieritas menunjukkan hubungan linear variabel self-esteem pada variabel kecenderungan anorexia nervosa $(p=0,801)$.

\section{I S K U S I}

Penelitian ini memiliki tujuan untuk mengetahui apakah ada hubungan antara self-esteem dengan kecenderungan anorexia nervosa pada remaja putri. Berdasarkan hasil uji korelasi yang telah dilakukan menggunakan metode Product Moment Pearson, menunjukkan bahwa variabel self-esteem memiliki hubungan yang signifikan terhadap variabel kecenderungan anorexia nervosa. Hubungan antar variabel bersifat negatif atau berlawanan arah, artinya semakin tinggi tingkat self-esteem maka semakin rendah tingkat kecenderungan anorexia nervosa. Hal itu sejalan dengan penelitian yang dilakukan oleh Zainab (2013) yang mengatakan bahwa self-esteem memiliki peranan penting terhadap terjadinya kecenderungan gangguan makan baik anorexia nervosa maupun bulimia nervosa. Penelitian yang dilakukan oleh Talwar (2012) juga menunjukkan bahwa self-esteem menjadi salah satu faktor penting dalam kecenderungan anorexia nervosa. Pada penelitian tersebut yang subjeknya merupakan mahasiswi dengan rentang usia 19-21 tahun yang memiliki self-esteem rendah akan lebih mudah mengarah pada kecenderungan anorexia nervosa daripada mahasiswi yang lebih tua usianya.

Partisipan dalam penelitian ini adalah remaja putri berusia 15-22 tahun sejalan dengan teori yang dikemukakan oleh Nevid, dkk (2018) bahwa gangguan makan seperti anorexia nervosa dan bulimia nervosa banyak terjadi pada remaja yang duduk di bangku Sekolah Menengah Atas (SMA) dan perguruan tinggi, serta paling banyak dialami oleh remaja putri. Pada masa remaja individu juga mengalami perubahan fisik, pada remaja putri seperti melebarnya ukuran pinggul, bertambahnya berat badan dan tinggi badan, maupun perubahan secara psikis (Santrock, 2010). Mengikuti perubahan yang terjadi, self-esteem pada remaja juga mengalami perubahan. Individu saat masa kanak-kanak memiliki self-esteem yang tinggi, namun pada usia remaja terjadi penurunan tingkat self-esteem, dan pada remaja putri self-esteem akan menurun secara drastis dibandigkan dengan remaja putra.

Saat ini, di kalangan remaja putri terdapat acuan bentuk tubuh ideal yaitu kurus, tinggi, serta langsing (Ratnawati \& Sofiah, 2012). Adanya ketidakpuasan tubuh pada remaja putri membuat mereka juga tidak bisa menghargai dirinya sendiri dan memandang dirinya rendah, itulah yang dinamakan dengan memiliki self-esteem rendah. Remaja putri yang memiliki self-esteem rendah dan merasa tidak puas dengan perubahan bentuk tubuhnya, mereka akan berusaha untuk menjadikan bentuk tubuhnya sesuai dengan acuan bentuk tubuh ideal. Demi mendapatkan tubuh yang ideal, remaja putri akan melakukan segala cara agar berat badannya berkurang seperti melakukan pembatasan pola makan, menolak makan meski lapar, atau menggunakan obat pencahar untuk mengurangi berat badan, dan jika berlebihan akan 
mengarah pada kecenderungan anorexia nervosa. mengarah pada kecenderungan anorexia nervosa atau gangguan makan lainnya. Hal tersebut juga sejalan dengan penelitian yang dilakukan oleh Zainab (2013) pada penari balet dan mayoritas subjeknya adalah remaja, bahwa semakin mereka merasa tidak puas terhadap bentuk tubuhnya seperti perut, payudara, pinggul, bokong, paha, dan betis akan membuat mereka melakukan perilaku makan yang menyimpang, dan mengarah pada semakin tingginya kecenderungan gangguan makan anorexia nervosa atau bulimia nervosa. Selain itu, dalam penelitian tersebut juga dikatakan bahwa semakin subjek bisa menghargai dirinya baik dari segi fisik maupun hal lain, maka akan mengurangi kemungkinan kecenderungan gangguan makan.

\section{S I M P U L A N}

Berdasarkan hasil analisis yang sudah dipaparkan, diketahui ada hubungan antara self-esteem dan kecenderungan anorexia nervosa pada remaja putri. Hubungan antara self-esteem dan anorexia nervosa adalah negatif atau berlawanan arah, artinya semakin tinggi tingkat self-esteem maka semakin rendah tingkat kecenderungan anorexia nervosa. Sebaliknya, semakin rendah tingkat self-esteem maka semakin tinggi tingkat kecenderungan anorexia nervosa.

Penelitian ini diharapkan dapat menjadi referensi untuk penelitian selanjutnya mengenai topik yang sama atau yang berkaitan dengan self-esteem dan kecenderungan anorexia nervosa. Selain itu, penelitian ini juga diharapkan bermanfaat untuk memberikan informasi kepada masyarakat mengenai hubungan antara self-esteem dengan kecenderungan anorexia nervosa, khususnya remaja putri. Saran bagi remaja putri sebaiknya mampu menerima segala perubahan bentuk tubuh yang terjadi secara positif dan mampu menghargai dirinya dengan tidak membandingkan diri dengan orang lain, tidak terpengaruh dengan orang lain maupun hal-hal yang akan menurunkan self-esteem, seperti bijak dalam memilah informasi yang berkaitan dengan tubuh ideal. Selain itu, apabila ingin melakukan penurunan berat badan, lakukan sesuai dengan aturan dan kebutuhannya supaya tetap aman dan menghasilkan tubuh yang sehat.

Penulis juga menyarankan kepada orang tua yang memiliki anak remaja putri untuk mampu mengajarkan pada anak pentingnya menghargai diri sendiri dengan menerima bentuk tubuhnya dan dirinya secara keseluruhan. Baik orang tua, teman-teman, maupun orang terdekat remaja putri lainnya, jika mengetahui anak atau teman yang merasa tidak menghargai dirinya, berikan dukungan positif, seperti memberikan kalimat motivasi, tidak mengatakan hal negatif mengenai kondisi fisik, dan memberi dukungan emosional agar remaja putri mampu melihat kualitas terbaik dirinya. Penulis juga menyarankan untuk penelitian selanjutnya dapat menambahkan variabel lain yang mungkin berhubungan dengan kecenderungan anorexia nervosa, selain itu dapat pula menggunakan metode kualitatif agar mampu memberi gambaran yang lebih jelas dan lebih dalam.

\section{U C A P A N T ERIMAKASIH}

Terima kasih kepada keluarga, teman-teman, dan partisipan yang telah mendukung dan membantu penulis dalam penyusunan penelitian ini. Terima kasih kepada seluruh dosen dan staf Fakultas Psikologi Universitas Airlangga yang telah membimbing dan memberikan fasilitas kepada penulis selama masa perkuliahan dan selama penyusunan penelitian ini. 


\section{DEKLARASI POTENSI TERJADINYA KONFLIK KEPENTINGAN}

Sekar Jingga Diwananda Islamy dan Ika Yuniar Cahyanti tidak bekerja, menjadi konsultan, memiliki saham, atau menerima dana dari perusahaan atau organisasi manapun yang mungkin akan mengambil untung dari diterbitkannya naskah ini.

\section{PUSTAKA ACUAN}

American Psychiatric Association. (1994). Diagnostic and statistical manual of mental disorders (4th ed.). Washington DC: American Psychiatric Association.

Azwar, S. (2018). Metode penelitian psikologi (2nd ed.). Yogyakarta: Pustaka Pelajar.

Beals, K. A. (2004). Disordered eating among athletes: A comprehensive guide for health professionals. Champaign: Human Kinetics.

Bearman, S. K., Presnell, K., Erin, M., \& Eric, S. (2006). The skinny on body dissatisfaction: A longitudinal study of adolescent girls and boys. Journal of Youth and Adolescence, 2(35), 217-229.

Burrows, A., \& Cooper, M. (2002). Possible risk factors in the development of eating disorders in overweight pre-adolescent girls. International Journal of Obesity, 26(9), 1268-1273.

Direktorat Jenderal Pelayanan Medik Departemen Kesehatan. (1993). Pedoman penggolongan dan diagnosis gangguan jiwa di Indonesia (PPDGJ) III (Cetaka). Direktorat Jenderal Pelayanan Medik Departemen Kesehatan.

Garner, D. ., Olmsted, M. P., Bohr, Y., \& Garfinkel, E. P. (1982). The eating attitudes tests: Psychometric features and clinical correlates. Psychological Medicine, (12), 871-878.

Heatherton, T., \& Polivy, J. (1991). Body dissatisfaction, self-focus, and dieting status among women. Psychology of Addicting Behaviors, 60(6), 895-910.

Impett, E. A., Schoolder, D., Tolman, L., Sorsoli, L., \& Henson, J. M. (2008). Girls' relationship authenticity and self-esteem across adolescence. Developmental Psychology, (44), 722-733.

Krisnani, H., Santoso, M. B., \& Putri, D. (2017). Gangguan makan anorexia nervosa dan bulimia nervosa pada remaja. Prosiding Penelitian Dan Pengabdian Kepada Masyarakat, 4(3), 390-447.

National Eating Disorders Association. (2018). Statistics and research on eating disorders. Retrieved April 26, 2021, from https://www.nationaleatingdisorders.org/statistics-research-eatingdisorders

Neuman, W. L. (2017). Understanding research second edition (2nd ed., Vol. 32). New York: Pearson.

Nevid, J. S., Rathus, S. A., \& Greene, B. (2018). Abnormal psychology (10th ed.). New York: Pearson Education, Inc.

Ratnawati, V., \& Sofiah, D. (2012). Percaya diri, body image, dan kecenderungan anorexia nervosa pada remaja putri. Persona, Jurnal Psikologi Indonesia, 1(2), 130-142.

Robins, R. W., Trzesniewski, K. H., Tracy, J. L., Gosling, S. D., \& Potter, J. (2002). Global self-esteem across

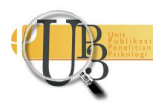


the life span. Psychology and Aging, 17(3), 423-434.

Rosenberg, M. (1965). Society and the adolescent self-image. Princeton: NJ: Princeton University Press.

Rosenberg, M. (1989). Society and the adolescent self image (Revised Ed). Middletown: CT: Wesleyan University Press.

Santrock, J. W. (2010). Life-span development (13th ed.). New York: McGraw-Hill.

Santrock, John W. (2007). Remaja (Jilid 1) (Sebelas). Jakarta: Erlangga.

Syarafina, A., \& Probosari, E. (2014). Hubungan eating disorder dengan status gizi pada remaja putri di modeling agency Semarang. Journal of Nutrition College, 1(2), 48-53.

Talwar P. (2012). Self-Esteem and anorectic eating concerns among female university students in Malaysia. In Malaysian Journal of Psychiatry (Vol. 21). Sarawak.

Tantiani, T., \& Syafiq, A. (2008). Perilaku makan menyimpang pada remaja di Jakarta. Kesmas: National Public Health Journal, 2(6), 255.

Wijaya, Y. M. A. (2018). Kecenderungan anorexia nervosa pada mahasiswi yang berstatus sebagai model. Universitas Islam Indonesia Yogyakarta.

Zainab, N. (2013). Peranan self-esteem dan body dissatisfaction dalam memprediksi kecenderungan eating disorders pada penari ballet. 46-49. 